\title{
Contents of Opticheskiu Zhurnal (Journal of Optical Technology), vol. 76, no. 5, 2009
}

PACS numbers: 01.10.Cr

DOI: $10.1134 /$ S0030400X09050270

The following papers will be published in the May issue of Opticheskil Zhurnal (Journal of Optical Technology), vol. 76, no. 5, 2009.

Physical Optics. Estimate of the Basic Parameters of a Waveguide Microresonator IR Image Converter (V.A. Pilipovich, A.K. Esman, V.K. Kuleshov, and G.L. Zykov).

Laser Physics and Technology. New Industrial Kilowatt-Power $\mathrm{CO}_{2}$ Waveguide Lasers with HighQuality Radiation (V.O. Aleksandrov, V.V. Budanov, V.V. Vasil'tsov, M.G. Galushkin, V.S. Golubev, E.N. Egorov, E.V. Zelenov, V.Ya. Panchenko, A.N. Semenov, A.V. Solov'ev, and E.V. Chashkin); Nonlinear and Electron-Beam-Induced Absorption in Pure Quartz Glasses at the Excimer Laser Wavelengths (P.B. Sergeev, A.P. Sergeev, and V.D. Zvorykin); Study of the Action of the 193- and 223-nm Excimer Laser Radiation on the Human Cornea in Refraction Surgery (A.M. Razhev, V.V. Chernykh, A.A. Zhupikov, S.V. Kostenev, and D.S. Churkin).

Computation, Design, and Manufacture of Optical Systems. Selection of an Optical System and Design of Small-Size Lenses for Mobile Telephones (I.G. Bronshtein, V.A. Zverev, I.L. Livshits, Kim Young-Gi, Kim Tae-Young, and Jung Phil-Ho); Optical Monitoring of the Air Pollution in Mexico City (M. Perevoshchikova, Romero Gabriel Eduardo Sandovale, and Dias Victor Argeta).

Iconics: The Science of Images. Reconstruction of Smeared Images without Using Boundary Conditions (V.S. Sizikov, M.V. Rimskikh, and V.V. Shempliner).
Holography. Relief Height Dependence of the Parameters of Spurious Nanostructuring of ReliefPhase Holographic Structures on Thin Vitreous Chalcogenide Semiconductor Films (S.N. Koreshev and V.P. Ratushnyi).

Optical Instrumentation and Technology. Study of the Thermal Stability of a Mirror Telescope-Solar Limbograph in the Continuous Sun Observation Mode (Kh.I. Abdusamatov, A.I. Bogoyavlenskiǔ, E.V. Lapovok, and S.I. Khankov).

Optical Materials Science and Technology. Metamaterials and the Problem of Creation of Invisible Objects: 2. Invisible Shells Concealing Objects Contained Therein from an External Observer (M.P. Shepilov and A.A. Zhilin); Development of the Kard Theory for Metal-Dielectric Filters (I.S. Gainutdinov, R.D. Aliakberov, R.R. Gareev, A.V. Mikhailov, and N.G. Mirkhanov); Antireflection Coatings on the Germaniun and Silicon Substrates for the Transparency Windows of 3-5 and 8-12 $\mu \mathrm{m}$ in the IR Spectral Range (I.S. Gainutdinov, N.Yu. Shuvalov, R.S. Sabirov, V.A. Ivanov, and R.R. Gareev).

Practical Manufacturing Problems. Properties of Multicomponent Achromatic and Superachromatic Zero-Order Wave Plates (A.V. Samoilov, V.S. Samoilov, A.S. Klimov, and E.A. Oberemok).

Compiled by L.V. Enushevskaya

Translated by S. Belov 